\title{
Permeability changes and effect of chemotherapy in brain adjacent to tumor in an experimental model of metastatic brain tumor from breast cancer
}

Afroz S. Mohammad, Chris E. Adkins, Neal Shah, Rawaa Aljammal, Jessica I. G. Griffith, Rachel M. Tallman, Katherine L. Jarrell and Paul R. Lockman*

\begin{abstract}
Background: Brain tumor vasculature can be significantly compromised and leakier than that of normal brain blood vessels. Little is known if there are vascular permeability alterations in the brain adjacent to tumor (BAT). Changes in BAT permeability may also lead to increased drug permeation in the BAT, which may exert toxicity on cells of the central nervous system. Herein, we studied permeation changes in BAT using quantitative fluorescent microscopy and autoradiography, while the effect of chemotherapy within the BAT region was determined by staining for activated astrocytes.

Methods: Human metastatic breast cancer cells (MDA-MB-231Br) were injected into left ventricle of female NuNu mice. Metastases were allowed to grow for 28 days, after which animals were injected fluorescent tracers Texas Red $(625 \mathrm{Da})$ or Texas Red dextran $(3 \mathrm{kDa})$ or a chemotherapeutic agent ${ }^{14} \mathrm{C}$-paclitaxel. The accumulation of tracers and ${ }^{14} \mathrm{C}$-paclitaxel in BAT were determined by using quantitative fluorescent microscopy and autoradiography respectively. The effect of chemotherapy in BAT was determined by staining for activated astrocytes.

Results: The mean permeability of texas Red (625 Da) within BAT region increased 1.0 to 2.5 -fold when compared to normal brain, whereas, Texas Red dextran $(3 \mathrm{kDa})$ demonstrated mean permeability increase ranging from 1.0 to 1.8-fold compared to normal brain. The $\mathrm{K}_{\text {in }}$ values in the BAT for both Texas Red (625 Da) and Texas Red dextran (3 $\mathrm{kDa}$ ) were found to be $4.32 \pm 0.2 \times 10^{5} \mathrm{~mL} / \mathrm{s} / \mathrm{g}$ and $1.6 \pm 1.4 \times 10^{5} \mathrm{~mL} / \mathrm{s} / \mathrm{g}$ respectively and found to be significantly higher than the normal brain. We also found that there is significant increase in accumulation of ${ }^{14} \mathrm{C}$-Paclitaxel in BAT compared to the normal brain. We also observed animals treated with chemotherapy (paclitaxel $(10 \mathrm{mg} / \mathrm{kg})$, erubilin $(1.5 \mathrm{mg} / \mathrm{kg})$ and docetaxel $(10 \mathrm{mg} / \mathrm{kg}))$ showed activated astrocytes in BAT.
\end{abstract}

Conclusions: Our data showed increased permeation of fluorescent tracers and ${ }^{14} \mathrm{C}$-paclitaxel in the BAT. This increased permeation lead to elevated levels of activated astrocytes in BAT region in the animals treated with chemotherapy.

Keywords: Brain metastases, Fluorescent microscopy, Autoradiography, Astrocytosis, Chemotherapy

\footnotetext{
* Correspondence: prlockman@hsc.wvu.edu

Department of Pharmaceutical Sciences, West Virginia University Health

Sciences Center, School of Pharmacy, 1 Medical Center Drive, Morgantown,

West Virginia 26506-9050, USA
}

(c) The Author(s). 2018 Open Access This article is distributed under the terms of the Creative Commons Attribution 4.0 International License (http://creativecommons.org/licenses/by/4.0/), which permits unrestricted use, distribution, and reproduction in any medium, provided you give appropriate credit to the original author(s) and the source, provide a link to the Creative Commons license, and indicate if changes were made. The Creative Commons Public Domain Dedication waiver (http://creativecommons.org/publicdomain/zero/1.0/) applies to the data made available in this article, unless otherwise stated. 


\section{Background}

The incidence of metastatic brain tumors in United States is approximately 170,000 patients annually [1]. The most common primary sites for brain metastases are lung, breast, and skin, with more than $70 \%$ of the patients account for cancers from lung and breast [2]. The incidence of breast cancer metastases to brain is increasing, as there is a significant improvement in 5-year survival from primary breast cancer $[3,4]$. Once diagnosed with metastatic brain tumors from breast cancer, 4 out of 5 patients will die within one year [5].

Conventional chemotherapy fails in metastatic brain tumors due to the presence of blood-brain barrier (BBB)/ blood-tumor barrier (BTB), which prevents a sufficient concentration of chemotherapeutics from reaching lesions [5]. However, we have previously found that there is an increase in drug permeation in metastatic lesions when compared to the normal brain [6, 7]. Many newer strategies to treat metastatic brain tumors include methods to improve chemotherapeutic penetration by overcoming the $\mathrm{BBB} / \mathrm{BTB}$, including nanoparticles, osmotic BBB disruption, BBB disruption using ultrasound, etc. [8-11]. All of these strategies have shown increased penetration through $\mathrm{BBB}$, but the effect of chemotherapy on tumor-adjacent healthy tissue has not been thoroughly investigated.

In this study, we hypothesize that the area around tumor is more accessible to drug penetration due to increased vascular permeability and diffusion from the tumor into normal brain tissues, which may result in chemotherapy accumulation and effect in the brain adjacent to tumor (BAT). We tested the penetration of two different fluorescent permeability markers, texas Red free dye (Mol. Wt. $625 \mathrm{Da}$.) and texas Red dextran $3 \mathrm{kDa}$. (Mol. wt. 3000 Da.). We then determined the distribution of ${ }^{14} \mathrm{C}$-paclitaxel in normal brain, tumors, and BAT regions. Finally, we studied the effect of chemotherapy on BAT by staining for a marker of neuro-inflammation.

\section{Methods}

\section{Chemicals \& reagents}

The fluorescent tracers Texas Red $(625 \mathrm{Da})$ and Texas Red dextran $(3 \mathrm{kDa})$ was purchased from Molecular Probes-Life Technologies (Carlsbad, CA). Dulbecco's modified eagle medium (DMEM) and Fetal bovine serum (FBS) were purchased from Gibco-Life Technologies (Carlsbad, CA). Cell culture flasks were purchased from Falcon (Corning, NY). Radiolabeled $\left({ }^{14} \mathrm{C}\right)$-Paclitaxel $(101 \mathrm{mCi} / \mathrm{mmol})$ was purchased from Moravek, Inc. (Brea, CA). Paclitaxel, docetaxel and eribulin was purchased from Selleckchem Chemicals (Houston, TX). Radiolabeled $\left({ }^{14} \mathrm{C}\right)$-Paclitaxel $(101 \mathrm{mCi} / \mathrm{mmol})$ was purchased from Moravek, Inc. (Brea, CA). Cresyl violet acetate $(0.1 \%)$ and Cremophore EL was purchased from
Sigma-Aldrich (St. Louis, MO). Anti-GFAP antibody (ab4674) was purchased from abcam (Cambridge, MA). All other chemicals and reagents used were of analytical grade and were used as supplied.

\section{Cell culture}

Human MDA-MB-231Br metastatic breast cancer cells were kindly donated as a gift by Dr. Patricia S. Steeg (Canter for Cancer Research, National Cancer Institute, Bethesda, MD). Human MDA-MB-231Br metastatic breast cancer cell line was created from the commercially available MDA-MB-231 cell line by Dr. Patricia Steeg's lab by repeated cycles of intra-cardiac injection and harvesting from brain metastases in mice $[6,7]$. The cells were cultured in DMEM supplemented with $10 \%$ FBS. MDA-MB-231Br cell lines were transfected to stably express the enhanced green fluorescent protein (eGFP). All cells used in experimental conditions came from passages $1-10$ and were maintained at $37^{\circ} \mathrm{C}$ with $5 \% \mathrm{CO}_{2}$. For all cell preparations for intracardiac injection, cells were harvested at 70\% confluency.

\section{Experimental brain metastases model}

All animal handling and procedures were approved by Institutional Animal Care and Use Committee protocol (WVU \#13-1207), and all work was conducted following the 1996 NIH Guide for the Care and Use of Laboratory Animals. Human ethics approval and informed consent for this study are not applicable because no human subjects were involved in this study. Female athymic nu/nu mice (24-30 g) were purchased from Charles River Laboratories (Wilmington, MA) and were used for the experimental metastases model in this study. Mice were 6 to 8 weeks of age at the initiation of the brain metastases models and were housed in a barrier facility with chow and water available ad libitum before and after inoculation of tumor cells. For inoculation of MDA-MB-231BR cells, mice were anesthetized under $2 \%$ isoflurane and injected with 175,000 cells in the left cardiac ventricle using a sterile 27 -gauge tuberculin syringe with the aid of a stereotaxic device (Stoelting, Wood Dale, IL) as previously reported by Adkins et al. [6]. Injection accuracy was evaluated by a pulsatory flash of bright-red blood into the syringe upon little retraction of the plunger prior to injection. After intra-cardiac injection, mice were placed in a warmed $\left(37^{\circ} \mathrm{C}\right)$ sterile cage and vitals monitored until fully recovered. Metastases were allowed to develop until neurologic symptoms like seizures, labored breathing, hunched posture and anorexia appeared ( 28 days for MDA-MB-231Br), and animals were then anesthetized with ketamine/xylazine $(100 \mathrm{mg} /$ $\mathrm{kg}$ and $8 \mathrm{mg} / \mathrm{kg}$ respectively) prior to Texas Red $625 \mathrm{Da}$ $(6 \mathrm{mg} / \mathrm{kg}$ in saline) and Texas Red dextran $3 \mathrm{kDa}(6 \mathrm{mg} /$ $\mathrm{kg}$ in saline $)$ and ${ }^{14} \mathrm{C}$-Paclitaxel $(10 \mu \mathrm{Ci} / \mathrm{animal}, 10 \mathrm{mg} / \mathrm{kg}$ 
in Taxol formulation, Moravek) injection via IV bolus dose (femoral vein). The Texas Red $625 \mathrm{Da}(n=6)$ and Texas Red dextran $3 \mathrm{kDa}(\mathrm{n}=6)$ were allowed to circulate for $10 \mathrm{~min}$ prior to euthanasia by decapitation, and ${ }^{14} \mathrm{C}$-Paclitaxel $(n=10)$ was allowed to circulate for $8 \mathrm{~h}$ before sacrifice by decapitation. The endpoints for texas red and ${ }^{14} \mathrm{C}$-Paclitaxel circulation times were determined by previous studies [7]. Brains were rapidly removed (less than $60 \mathrm{~s})$, flash-frozen in isopentane $\left(-65^{\circ} \mathrm{C}\right)$, and stored at negative $20^{\circ} \mathrm{C}$.

\section{Tissue processing and analysis}

Brain slices $(20 \mu \mathrm{m})$ were acquired with a cryotome (Leica CM3050S; Leica Microsystems, Wetzlar, Germany) and transferred to charged microscope slides. Fluorescent images of brain slices were acquired using a stereomicroscope (Olympus MVX10; Olympus, Center Valley, PA) equipped with a 0.5 NA $2 \mathrm{X}$ objective and a monochromatic cooled CCD scientific camera (Retiga 4000R, QIMaging, Surrey, BC, Canada). Texas Red fluorescence was imaged using a DsRed sputter filter (excitation/band $\lambda 545 / 25 \mathrm{~nm}$, emission/band $\lambda$ 605/70 $\mathrm{nm}$ and dichromatic mirror at $\lambda 565 \mathrm{~nm}$ ) (Chroma Technologies, Bellows Falls, VT) and enhanced green fluorescent protein (expressed in MDA-MB-231Br) using an ET-GFP sputter filter (excitation/band $\lambda 470 / 40 \mathrm{~nm}$, emission/band $\lambda 525 / 50 \mathrm{~nm}$ and dichromatic mirror at $\lambda$ $495 \mathrm{~nm}$ ) (Chroma Technologies, Bellows Falls, VT). Fluorescent image capture and analysis software (SlideBook 5.0; Intelligent Imaging Innovations Inc., Denver, $\mathrm{CO}$ ) was used to capture and quantitate images. Binary mask methodology was used to analyze brain slices based upon the eGFP fluorescence from MDA-MB-231Br cells. Binary mask methodology is simply voxel-defined regions of interest where tumor was defined by the presence of eGFP fluorescence from MDA-MB-231Br on a voxel-by-voxel basis. By this methodology, the eGFP fluorescence roughly $>3$-fold above background was considered a brain tumor. Once the images were acquired, circumferential fluorescent analysis was performed using software analysis (SlideBook 5.0; Intelligent Imaging Innovations Inc., Denver, $\mathrm{CO}$ ), where $8-\mu \mathrm{m}$ thick region of interest (ROI) were drawn $300 \mu \mathrm{m}$ beyond and within the tumor (Fig. 1a and b). Texas red permeability
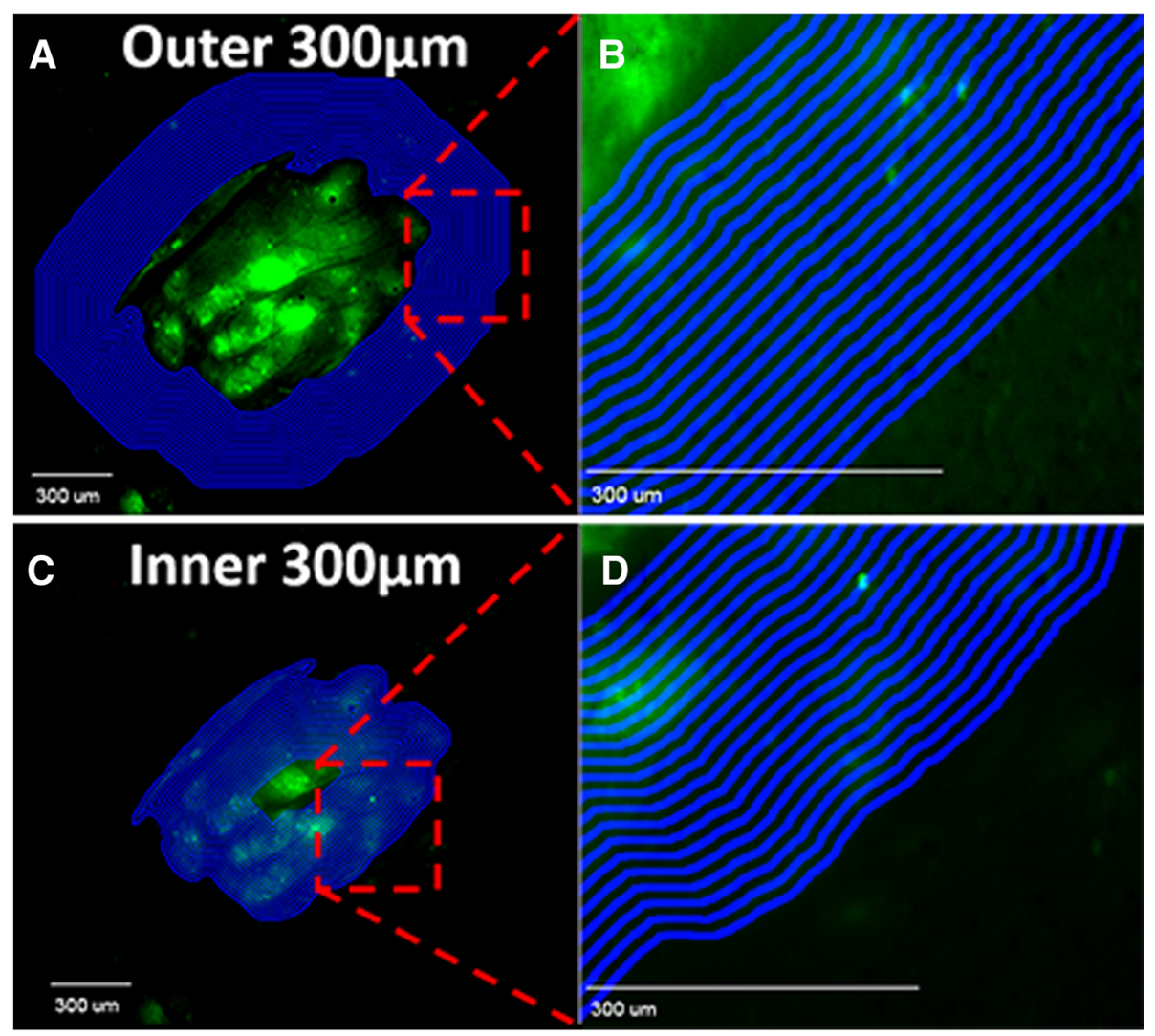

Fig. 1 Circumferential Fluorescent Analysis by Quantitative Fluorescence Microscopy. Fluorescent image of eGFP transfected MDA-MB-231Br metastasis in brain with circumferential $8 \mu \mathrm{m}$ thick regions of interest (ROI) drawn to $300 \mu \mathrm{m}$ beyond the metastasis margin (a and $\mathbf{b})$. To distinguish between BAT and tumor regions, the inner $300 \mu \mathrm{m}$ from the metastasis margin were used to create $8 \mu \mathrm{m}$ thick circumferential ROls (c and $\mathbf{d}$ ) 
fold-changes were determined by Texas Red sum intensity (SI) per unit area of metastases relative to that of contralateral normal brain regions. The transfer coefficient $\left(\mathrm{K}_{\mathrm{in}}\right)$ of Texas Red tracers were determined in tumor, BAT and normal brain by multiple uptake time approach after analyzing the blood and tumor concentrations of Texas Red tracers as previously described by Mittapalli et al. [12].

The unidirectional blood to brain, blood to tumor and blood to BAT transfer constant $\mathrm{K}_{\text {in }}$ was determined for fluorescent tracers using single-time uptake approach [13-15]. A single-time uptake method was used to calculate $\mathrm{K}_{\text {in }}$ because of heterogeneity of the metastatic tumors. $K_{i n}$ was calculated using the following equation $[12,15]$

$$
\mathrm{K}_{i n}=\frac{C_{b r}(T)}{\int_{0}^{t} C_{b l}(T) d t}
$$

Where, $\mathrm{C}_{\mathrm{br}}$ is the amount of compound in brain/metastatic tumor/ BAT per unit mass of the tissue at time $\mathrm{T}$ and $\mathrm{C}_{\mathrm{bl}}$ is the blood concentration of the tracer.

For ${ }^{14} \mathrm{C}$-Paclitaxel permeation studies, $20 \mu \mathrm{m}$ thick brain slices were exposed for 20 days to phosphor screens along with tissue-calibrated standards for quantitative autoradiographic analysis. The phosphor screens were developed using GE Typhoon FLA 7000 and images were processed using MCID software (Imaging Research) and Adobe Photoshop to acquire color-coded drug concentrations $(\mathrm{ng} / \mathrm{g}$ or $\mu \mathrm{g} / \mathrm{g})$ in regions of interest.

\section{Effect of drugs on BAT}

Female athymic nu/nu mice were inoculated with human MDA-MB-231-Br-Luc cells and allowed to develop metastases. On day 21, the presence of metastases was confirmed using an IVIS bioluminescent imaging system and animals are randomly divided into four treatment groups ( $n=10$ /group) and then treated with Vehicle $(n=10$, saline), Docetaxel (10 mg/kg I.V, once a week, $n=10)$, Eribulin $(1.5 \mathrm{mg} / \mathrm{kg}$ I.P, twice every week, $\mathrm{n}=10)$ and Paclitaxel $(10 \mathrm{mg} / \mathrm{kg}$ I.V, once a week, $\mathrm{n}=10)$. Docetaxel and Eribulin was dissolved in a vehicle composed of $5 \%$ Tween 80 and 5\% Ethanol in saline, whereas paclitaxel was dissolved in a vehicle composed of 1:1 blend of Cremophor EL and ethanol was then diluted (nine parts of saline to one part of blend) with normal saline for administration. The treatment regimen was continued until mice showed neurological symptoms, and the then mice were sacrificed and the brains were harvested. The brains were sectioned and stained for glial fibrillary acidic protein (GFAP) for the presence of activated astrocytes in BAT region.

\section{Data analysis}

The unidirectional blood-to-brain, blood-to-tumor and blood-to-BAT transfer constant $\mathrm{K}_{\text {in }}$ differences were compared by one-way ANOVA with multiple comparisons (GraphPad ${ }^{\circledR}$ Prism 6.0, San Diego, CA) and were considered statistically significant at $p<0.05$. MCID software (Imaging Research Inc., UK) was used to quantify permeation of ${ }^{14} \mathrm{C}$-Paclitaxel in brain metastases, BAT and normal brain.

\section{Results \\ BAT permeability}

Regional barrier integrity was evaluated using permeability tracers, Texas Red 625 Da and Texas Red dextran (3 $\mathrm{kDa}$ ), which fall within the upper-limit molecular weight of most conventional and non-biological chemotherapeutic drugs. The margins of metastases were demarcated based on eGFP fluorescence around cancer cell clusters that were confined within $100 \mu \mathrm{m}$ of each other, as previously described (8). Once the tumor margin was defined for each metastasis, a series of consecutive circumferential masks ( $8 \mu \mathrm{m}$ wide) extending $300 \mu \mathrm{m}$ beyond the original metastasis margin were generated automatically using custom written SlideBook 5.0 software scripts (Fig. 1a and b). The additional $200 \mu \mathrm{m}$ region was drawn to also allow for analysis of brain distant to tumor. Additional circumferential masks $(8 \mu \mathrm{m}$ wide) that extend $300 \mu \mathrm{m}$ internally from the metastasis margin were created using the software scripts (Fig. 1c and d).

Texas Red $625 \mathrm{Da}$ and Texas Red Dextran $3 \mathrm{kDa}$ permeation were plotted relative to the distance from the tumor edge for different metastases exhibiting different magnitudes of mean permeability increases (Fig. 2a). Analysis of Texas Red $3 \mathrm{kDa}$ permeation within the BAT region $100 \mu \mathrm{m}$ beyond the tumor edge for each metastasis demonstrated mean permeability increase ranging from 1.0 to 1.8 -fold compared to normal brain (Fig. 2b). The mean permeability of Texas Red $625 \mathrm{Da}$ within BAT region increased 1.0 to 2.5 -fold when compared to normal brain.

We then calculated $K_{\text {in }}$ for tumor, normal brain, and BAT, and we found that there was a significant increase in $K_{i n}$ in BAT for both Texas Red free dye and Texas Red Dextran $3 \mathrm{kDa}$ when compared with normal brain (Fig. 3a and b). The $K_{\text {in }}$ values for Texas Red $625 \mathrm{Da}$ in normal brain was found to be $1.2 \pm 0.16 \times 10^{5} \mathrm{~mL} / \mathrm{s} / \mathrm{g}$. For tumor, it was $11.3 \pm 1.9 \times 10^{5} \mathrm{~mL} / \mathrm{s} / \mathrm{g}$, and for BAT the $K_{\text {in }}$ was $4.32 \pm 0.2 \times 10^{5} \mathrm{~mL} / \mathrm{s} / \mathrm{g}$. The $K_{\text {in }}$ values for Texas Red $3 \mathrm{kDa}$ was found to be $0.4 \pm 0.14 \times 10^{5} \mathrm{~mL} / \mathrm{s} /$ g, $2 \pm 0.3 \times 10^{5} \mathrm{~mL} / \mathrm{s} / \mathrm{g}$ and $1.6 \pm 1.4 \times 10^{5} \mathrm{~mL} / \mathrm{s} / \mathrm{g}$ for normal brain, tumor and BAT respectively.

\section{Distribution of paclitaxel in normal brain, BAT and tumor} After analyzing Texas Red tracer permeability and transfer coefficients in the BAT, we determined the distribution of ${ }^{14} \mathrm{C}$-Paclitaxel using autoradiography. The tumor was identified by cresyl violet stain (Fig. 4a) and the corresponding overlaid autoradiogram (Fig. 4b) was used to 


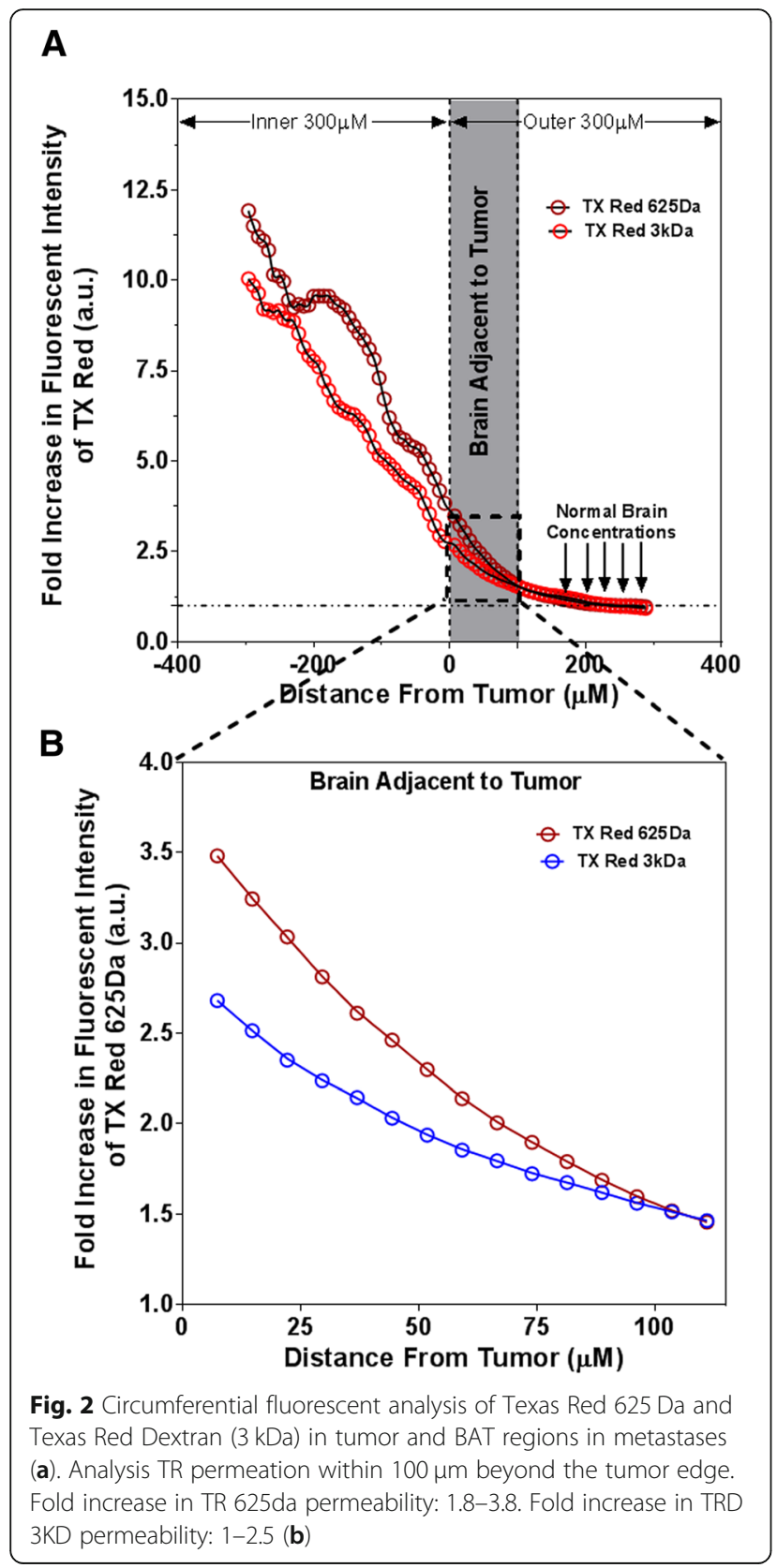

analyze the concentrations of paclitaxel in $100 \times 100 \mu \mathrm{m}$ squares $(50 \times 50 \mu \mathrm{m}$ squares in BAT $)$ as shown in Fig. $4 \mathrm{a}$ and $b$. We found that there is increase in the concentration of ${ }^{14} \mathrm{C}$-Paclitaxel in BAT regions and the increase in concentration was heterogeneous as seen in the metastases. We found that the concentration of ${ }^{14} \mathrm{C}$-paclitaxel in BAT $(0-50 \mu \mathrm{m})$ to be $86.7 \pm 31 \mathrm{ng} / \mathrm{g}$ and BAT (50$100 \mu \mathrm{m}) 35.4 \pm 11 \mathrm{ng} / \mathrm{g}$ (Fig. 4c), whereas the concentrations of ${ }^{14} \mathrm{C}$-Paclitaxel beyond $100 \mu \mathrm{m}$ of tumor and normal brain was consistently found to be $1 \mathrm{ng} / \mathrm{g}$. The concertation of ${ }^{14} \mathrm{C}$-Paclitaxel in the tumor was $529 \pm$ $223 \mathrm{ng} / \mathrm{g}$ consistent with our previous studies [7].

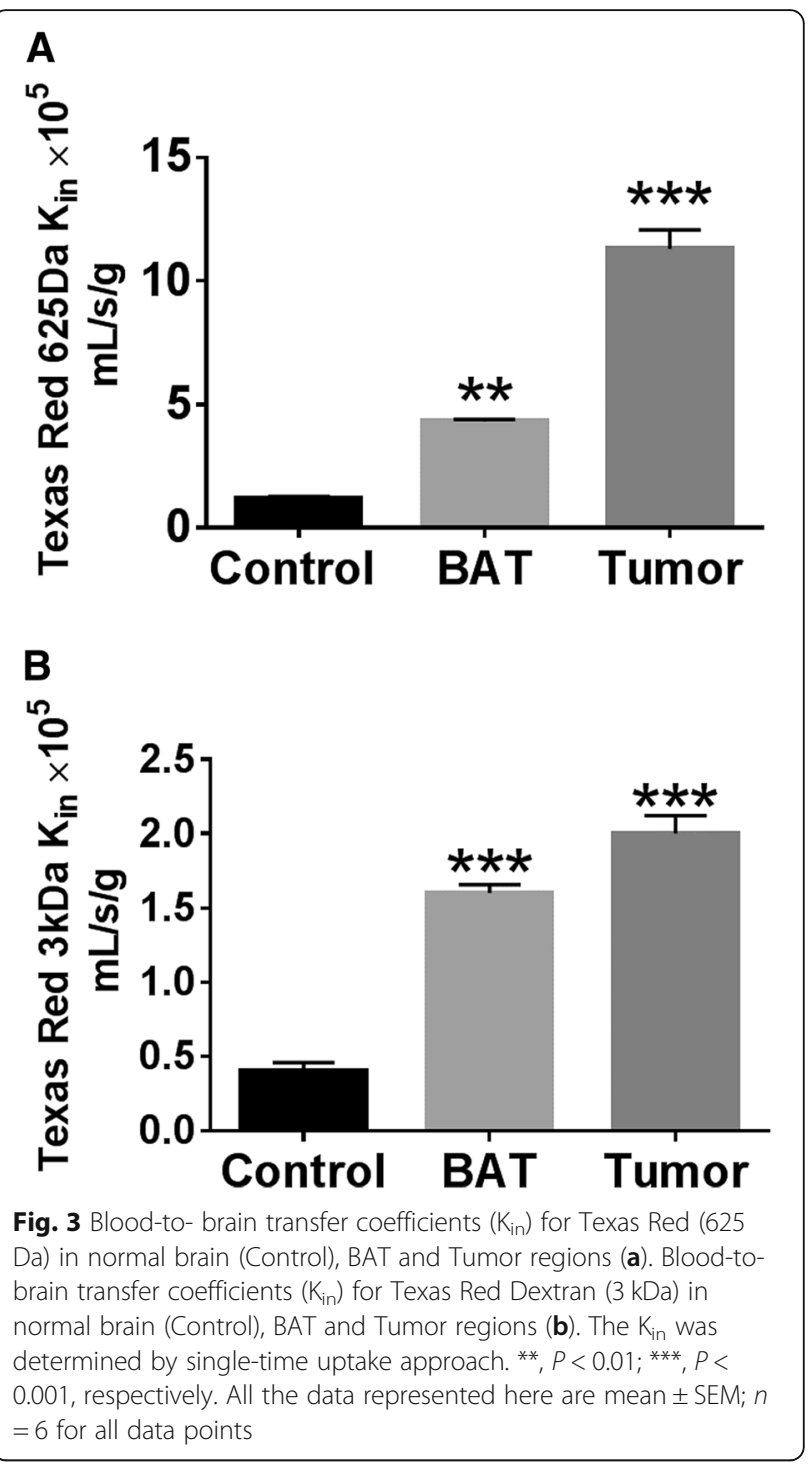

Chemotherapeutic drugs induce astrocyte activation in BAT After studying the permeability of tracers and ${ }^{14} \mathrm{C}$-paclitaxel in BAT, we sought to study the effect of chemotherapeutic drugs on BAT. For this study, we treated mice with various chemotherapeutic drugs after the confirmation of metastases as mentioned above. To visualize activated astrocytes, we stained for glial fibrillary acidic protein (GFAP), which is over-expressed when astrocytes are activated [16]. We observed GFAP over-expression in BAT in all the groups treated with chemotherapeutic drugs and found that there is an increase in expression of GFAP in BAT (Fig. 5b-d). However, GFAP expression in BAT in saline treated group was not noticeable (Fig. 5a).

\section{Discussion}

Many studies have shown the permeability and effect of chemotherapy in the brain metastases [7], but surprisingly, there are not many studies investigating those 

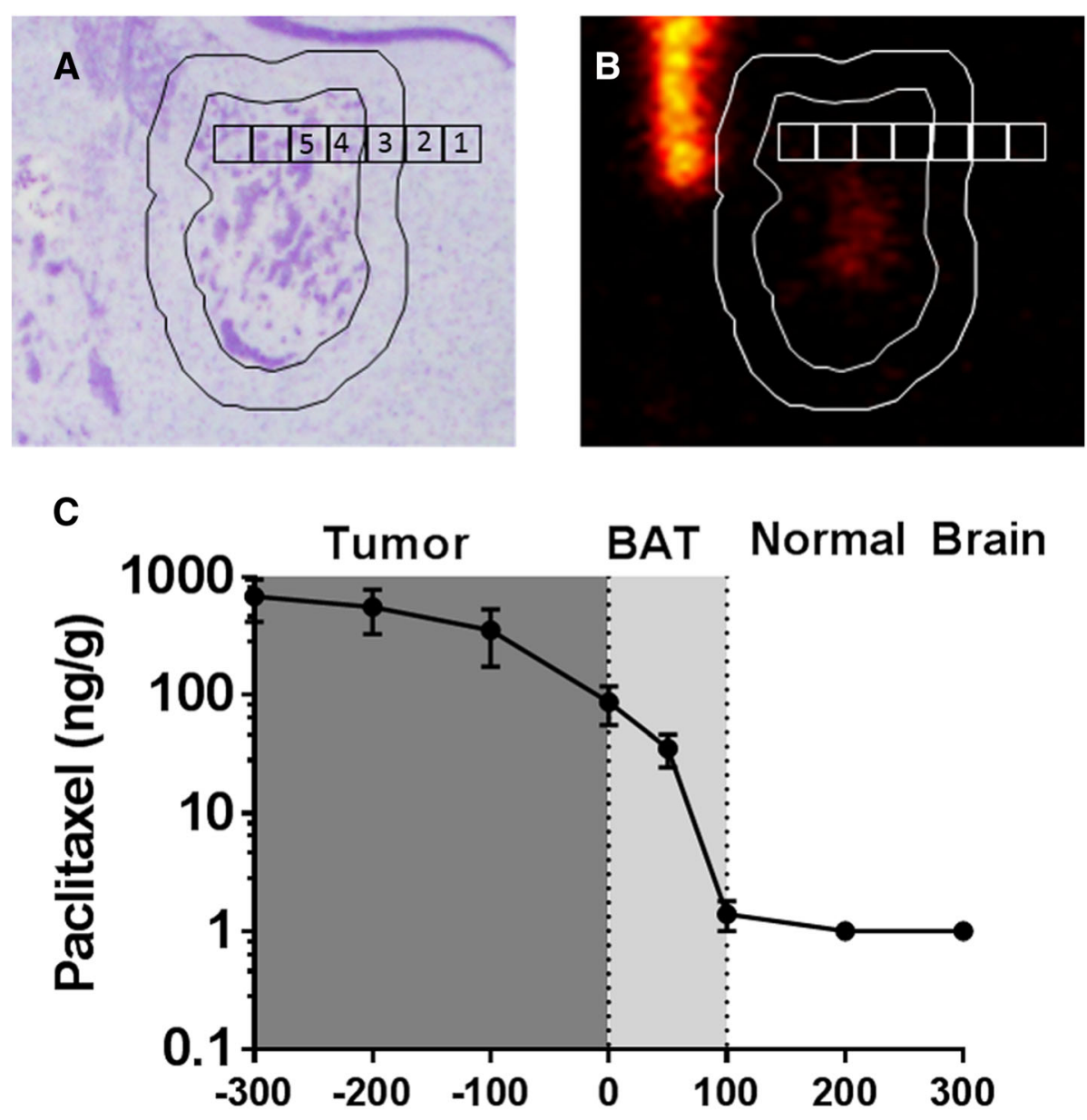

\section{Distance From Tumor $(\mu \mathrm{M})$}

Fig. 4 Representative image of $231 \mathrm{Br}$ brain metastases (a) and corresponding ${ }^{14} \mathrm{C}$-Paclitaxel accumulation (b) in metastases $8 \mathrm{~h}$ after intravenous administration of radiolabeled paclitaxel. Paclitaxel concentrations from $100 \mu \mathrm{m}$ squares as shown in image A and B were determined $(\mathbf{1}=1 \mathrm{ng} / \mathrm{g}$, $\mathbf{2}=1 \mathrm{ng} / \mathrm{g}, \mathbf{3}=10.5 \mathrm{ng} / \mathrm{g}, \mathbf{4}=293 \mathrm{ng} / \mathrm{g}, \mathbf{5}=261 \mathrm{ng} / \mathrm{g})$. (c) Analysis of ${ }^{14} \mathrm{C}-$ Paclitaxel concentration in tumor regions $(-300 \mathrm{\mu m}$ to 0$)$ and normal brain regions ( 0 to $300 \mu \mathrm{m}$ ). Data are mean $\pm \mathrm{SEM} ; n=15$ for all data points

same effects in BAT. With increase in strategies to overcome BBB and BTB to treat metastases $[1,9,10]$, it is important to study the permeability in BAT and effect of chemotherapy in metastatic tumors. In this study, we found that the permeability of tracers and ${ }^{14} \mathrm{C}$-palcitaxel increased in BAT when compared to normal brain regions distant to the tumor. We also found that administration of chemotherapeutic drugs induced activation of astrocytes in these adjacent regions.

In this work, we studied permeability for two tracers, Texas red $625 \mathrm{Da}$ and Texas red dextran $3 \mathrm{kDa}$ using quantitative fluorescence microscopy. The methodology was developed based on previous study by Mittapalli et al., [12], where all fluorescent images were captured using the same settings in the microscope to maintain uniformity in fluorescence emission [17]. Permeation of Texas red tracers in brain metastases were previously characterized by Adkins et al. [18], and we found similar fold-increase in tumor core. Unidirectional BBB/BTB transfer constants $K_{\text {in }}$ for both dyes were calculated using an established multiple-time uptake approach [13]. The $K_{\text {in }}$ values obtained in these studies for normal brain and tumor were consistent with our previous published data [12]. The increased $K_{\text {in }}$ values in BAT when compared to normal brain clearly suggest the permeability in BAT region was increased.

Once we had confirmed the increase in permeability of the tracers, we studied the distribution of a chemotherapeutic agent, ${ }^{14} \mathrm{C}$-paclitaxel in BAT. We used quantitative autoradiography (QAR) to determine the 

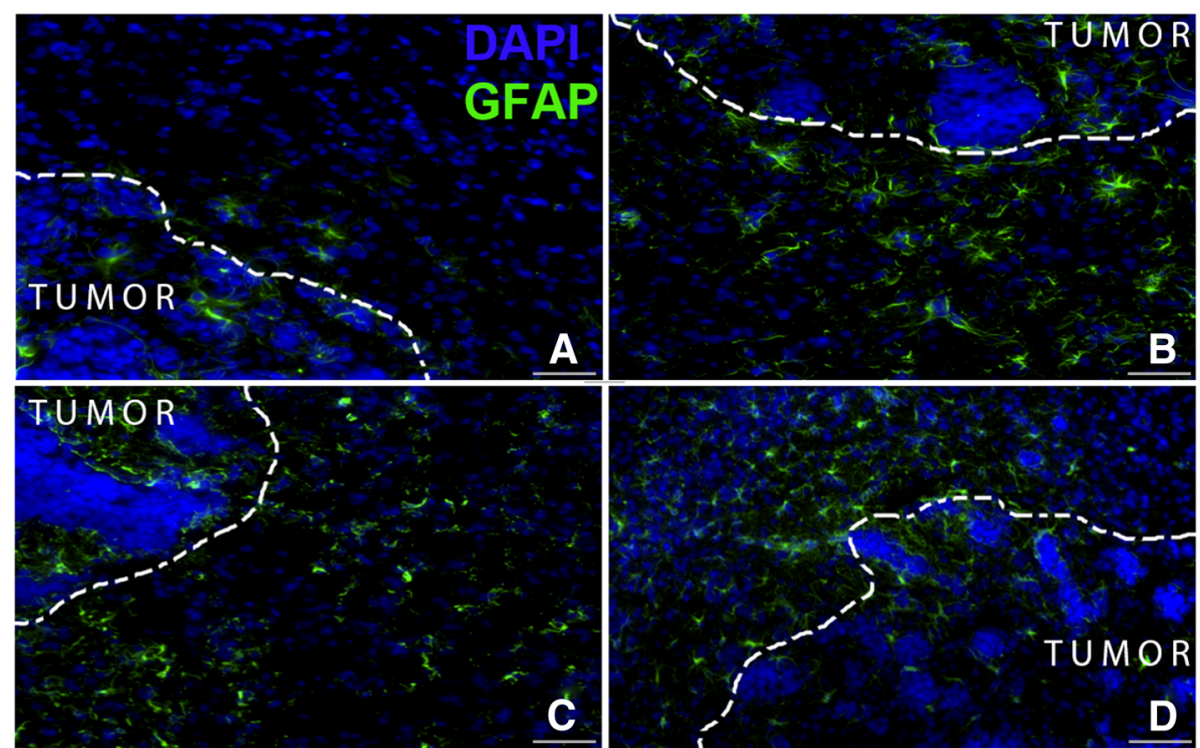

Fig. 5 Fluorescent images representing presence of nuclei (DAPI) in blue and activated astrocytes (GFAP) in green after treating with a.Saline (Vehicle), b. Eribulin (1.5 mg/kg I.P), c. Docetaxel: (10 mg/kg I.V), d. Paclitaxel: (10 mg/kg I.V). The GFAP expression in BAT regions in chemotherapeutic treated group appears are higher than that of vehicle group. Scale bar $=50 \mu \mathrm{m}$

distribution of ${ }^{14} \mathrm{C}$-paclitaxel in BAT, normal brain, and within the tumor $[19,20]$. We found that there is an increase in accumulation of ${ }^{14} \mathrm{C}$-paclitaxel in the BAT region and this increase is heterogeneous similar to what we have found in brain lesions previously [7]. The increase in permeation of BTB can be accounted for angiogenesis in the tumor [21-23] and the reasons for this heterogeneous permeability within the lesion is due to dynamics of angiogenic process as reported in the previous studies [24]. Also, the vascular endothelial growth factor (VEGF) secreted during tumor angiogenesis disrupt the tight junctions of the BBB which may lead to increased vascular permeability in the BAT $[25,26]$.

The most common transport mechanism for drugs across BBB is through passive diffusion [27]. For passive diffusion of drugs across the $\mathrm{BBB}$, the drugs which are lipid soluble, low molecular weight $(<400 \mathrm{Da})$ and which form $\leq 7$ hydrogen bonds are better candidates [28]. Diffusion through lipid membrane like BBB is dependent on molecular volume of the solute, which in turn depends on its molecular weight $[29,30]$. BBB permeability decreases 100 fold with the increase is solute's molecular weight from $300 \mathrm{Da}$ to $450 \mathrm{Da}$ [31]. In addition to solute related limitations, the active efflux transporters like p-glycoprotein (P-gp) and other members of ABC (ATP-binding cassette) family of transporters present at the $\mathrm{BBB}$ play a significant role in efflux of chemotherapeutic agents from the brain to blood [32, 33]. However, in metastatic lesions the BBB is disrupted (BTB) which results in an increase in penetration of chemotherapeutic agents [34].
The higher tumor concentration of chemotherapeutic agents in the tumor creates a concentration gradient with the surrounding normal brain allowing the chemotherapeutic agent to diffuse into normal brain [35]. Other studies observed increased blood flow in brain metastases and when compared to normal brain. Regarding permeability, the blood-to-tissue transfer constant $\left(\mathrm{K}_{\mathrm{i}}\right)$ for ${ }^{14} \mathrm{C}$ - $\alpha$-aminoisobutyric acid (AIB) was increased in both tumor and BAT when compared to normal brain, suggesting irregular neovascularization with increased permeability in the brain metastases [36-38].

Finally, once we confirmed the increased permeation of tracers and increased distribution of ${ }^{14} \mathrm{C}$-paclitaxel in BAT, we studied the effect of chemotherapy on BAT. After treating with various chemotherapeutic agents, we stained for GFAP to determine whether there was any inflammatory effect of chemotherapeutic drugs in CNS. GFAP is expressed in astrocytes in the brain [39], and when there is injury, inflammation or neurodegeneration in the central nervous system (CNS), the common reaction of astrocytes is hypertrophy, referred to as reactive astrocytosis or activated astrocytes [40-42]. This hypertrophy increases the expression of GFAP in astrocytes as well as the binding affinity to GFAP antibody [43]. Expression of GFAP is altered by many factors like brain injury and disease [16]. Many earlier studies reported the increase in GFAP expression in various diseases such as Alzheimer's, Amyotrophic lateral sclerosis (ALS), Parkinson's, Pick's, Huntington's and Autism [44-48]. In Autism, increase in autoantibodies of GFAP has also been found in plasma $[49,50]$. In the case of acute CNS 
injuries like brain infarction and traumatic brain injury, there was increase in levels of GFAP in CSF $[51,52]$. On the other hand, decrease in GFAP expression was associated with depression and growth of gliomas [53, 54]. We found that treating with chemotherapy, increased the expression of GFAP protein in BAT (Fig. 5), confirming the presence of activated astrocytes after pharmacological chemotherapy regimens.

Recent studies indicate, chemotherapy may induce numerous deleterious effects within CNS such as altered cognitive function, memory and attention [55]. Fading of cognitive function after chronic chemotherapy administration in patients with cancer has been termed "chemo-fog" or "chemo-brain" [56]. With improvements in survival for women with breast cancer over the past decade, there is also increased number of survivors expressing concerns with memory and concentration post treatment [57-59]. Recent studies suggest that the mechanism for chemo-fog is secondary to the toxic effects imposed by sub-lethal concentrations of chemotherapy on the normal cellular population of CNS [60]. Many studies suggests that chemotherapeutic agents not only induce oxidative stress and apoptosis in CNS but they also inhibit proliferation and differentiation of cellular population of CNS leading to abnormal expression of neurotrophic proteins in the brains [61-64].

\section{Conclusions}

In summary, we observed permeation of fluorescent tracers were increased in the BAT compared to normal brain, which was accompanied by increased distribution of ${ }^{14} \mathrm{C}$-paclitaxel. This increase in permeation resulted in increased uptake of chemotherapeutic agents and increased the expression of GFAP in regions adjacent to tumor, indicating reactive astrocytosis. As many new clinical strategies to treat brain metastases tend to increase drug permeation, it is also important to study potential damage in normal brain.

\section{Abbreviations}

BAT: Brain adjacent to tumor; BBB: Blood-brain barrier; BDT: Brain distant from tumor; BLI: Bio-luminescence imaging; BTB: Blood-tumor barrier; CNS: Central nervous system; EPR: Enhanced permeation and retention; GFAP: Glial fibrillary acidic protein; P-gp: P-Glycoprotein; QAR: quantitative autoradiography; SEM: Standard error of the mean

\section{Acknowledgements}

We would like to acknowledge National Cancer Institute and the National Institute of General Medical Sciences of the National Institutes of Health for funding this project.

\section{Funding}

The design of the study, experimental work, collection, analysis, and interpretation of data and writing the manuscript were funded by a grant from National Cancer Institute (R01CA166067-01A1/ R01CA166067-05). Interpretation of data and writing of manuscript were also funded by National Institute of General Medical Sciences of the National Institutes of Health (CTSI Award: U54GM104942). Microscopy imaging and image analysis were funded by National Institute of General Medical Sciences of the
National Institutes of Health (the COBRE P30 GM103488). Funding body had no role in the design of the study and collection, analysis, and interpretation of data and in writing the manuscript.

\section{Availability of data and materials}

The data generated and analyzed during this study are available from the corresponding author on reasonable request.

\section{Author's contributions}

ASM Conception and design, experimental work, analysis and interpretation of data, writing and review and approval of manuscript. CEA Conception and design, experimental work, analysis and interpretation of data, writing and review and approval of manuscript. NS Experimental work, analysis and interpretation of data review and approval of manuscript. RA Experimental work, analysis and interpretation of dAbsata review and approval of manuscript. JIGG Analysis of data, writing and review and approval of manuscript. RMT Experimental work, review and approval of manuscript. KLJ Experimental work, review and approval of manuscript. PRL Conception and design, analysis and interpretation of data, writing and review and approval of manuscript. Each author has read and approved the final version of the manuscript.

\section{Ethics approval and consent to participate}

All animal handling and procedures were approved by Institutional Animal Care and Use Committee at West Virginia University, Morgantown, West Virginia, USA (protocol number 13-1207).

\section{Consent for publication}

Not applicable.

\section{Competing interests}

The authors declare that they have no competing interests.

\section{Publisher's Note}

Springer Nature remains neutral with regard to jurisdictional claims in published maps and institutional affiliations.

Received: 10 August 2017 Accepted: 20 November 2018

Published online: 07 December 2018

\section{References}

1. Platta CS, Khuntia D, Mehta MP, Suh JH. Current treatment strategies for brain metastasis and complications from therapeutic techniques: a review of current literature. Am J Clin Oncol. 2010;33(4):398-407.

2. Rivkin M, Kanoff RB. Metastatic brain tumors: current therapeutic options and historical perspective. The Journal of the American Osteopathic Association. 2013;113(5):418-23.

3. Leone JP, Leone BA. Breast cancer brain metastases: the last frontier. Experimental Hematology \& Oncology. 2015;4(1):33.

4. Frisk $G$, Svensson T, Bäcklund LM, Lidbrink E, Blomqvist P, Smedby KE. Incidence and time trends of brain metastases admissions among breast cancer patients in Sweden. Br J Cancer. 2012;106(11):1850-3.

5. Adkins CE, Nounou MI, Mittapalli RK, Terrell-Hall TB, Mohammad AS, Jagannathan R, Lockman PR. A novel preclinical method to quantitatively evaluate early-stage metastatic events at the murine blood-brain barrier. Cancer prevention research (Philadelphia Pa). 2015;8(1):68-76.

6. Adkins CE, Mohammad AS, Terrell-Hall TB, Dolan EL, Shah N, Sechrest E, Griffith J, Lockman PR. Characterization of passive permeability at the blood-tumor barrier in five preclinical models of brain metastases of breast cancer. Clinical \& Experimental Metastasis. 2016;33(4):373-83.

7. Lockman PR, Mittapalli RK, Taskar KS, Rudraraju V, Gril B, Bohn KA, Adkins CE, Roberts A, Thorsheim HR, Gaasch JA, et al. Heterogeneous blood-tumor barrier permeability determines drug efficacy in experimental brain metastases of breast cancer. Clinical cancer research : an official journal of the American Association for Cancer Research. 2010;16(23):5664-78.

8. Adkins CE, Nounou MI, Hye T, Mohammad AS, Terrell-Hall T, Mohan NK, Eldon MA, Hoch U, Lockman PR. NKTR-102 efficacy versus irinotecan in a mouse model of brain metastases of breast cancer. BMC Cancer. 2015;15:685.

9. Guillaume DJ, Doolittle ND, Gahramanov S, Hedrick NA, Delashaw JB, Neuwelt EA. Intra-arterial chemotherapy with osmotic blood-brain barrier 
disruption for aggressive Oligodendroglial tumors: results of a phase I study. Neurosurgery. 2010;66(1):48-58.

10. Konofagou EE, Tung Y YS, Choi J, Deffieux T, Baseri B, Vlachos F. Ultrasoundinduced blood-brain barrier opening. Curr Pharm Biotechnol. 2012;13(7):1332-45.

11. El-Habashy SE, Nazief AM, Adkins CE, Wen MM, El-Kamel AH, Hamdan AM, Hanafy AS, Terrell TO, Mohammad AS, Lockman PR, et al. Novel treatment strategies for brain tumors and metastases. Pharmaceutical patent analyst. 2014;3(3):279-96.

12. Mittapalli RK, Adkins CE, Bohn KA, Mohammad AS, Lockman JA, Lockman PR. Quantitative fluorescence microscopy measures vascular pore size in primary and metastatic brain tumors. Cancer Res. 2017;77(2):238-46.

13. Patlak CS, Blasberg RG, Fenstermacher JD. Graphical evaluation of blood-tobrain transfer constants from multiple-time uptake data. J Cereb Blood Flow Metab. 1983;3(1):1-7.

14. Asotra K, Ningaraj N, Black KL. Measurement of blood-brain and bloodtumor barrier permeabilities with [14C]-labeled tracers. Methods in molecular medicine. 2003;89:177-90.

15. Blasberg RG, Shapiro WR, Molnar P, Patlak CS, Fenstermacher JD. Local blood-to-tissue transport in Walker 256 metastatic brain tumors. J NeuroOncol. 1984;2(3):205-18.

16. Eng LF, Ghirnikar RS, Lee YL. Glial fibrillary acidic protein: GFAP-thirty-one years (1969-2000). Neurochem Res. 2000;25(9):1439-51.

17. Song L, Varma CA, Verhoeven JW, Tanke HJ. Influence of the triplet excited state on the photobleaching kinetics of fluorescein in microscopy. Biophys J. 1996;70(6):2959-68.

18. Bohn KA, Adkins CE, Mittapalli RK, Terrell-Hall TB, Mohammad AS, Shah N, Dolan EL, Nounou MI, Lockman PR. Semi-automated rapid quantification of brain vessel density utilizing fluorescent microscopy. J Neurosci Methods. 2016;270:124-31.

19. Knight RA, Karki K, Ewing JR, Divine GW, Fenstermacher JD, Patlak CS, Nagaraja TN. Estimating blood and brain concentrations and blood-to-brain influx by magnetic resonance imaging with step-down infusion of Gd-DTPA in focal transient cerebral ischemia and confirmation by quantitative autoradiography with Gd-[(14)C]DTPA. Journal of cerebral blood flow and metabolism : official journal of the International Society of Cerebral Blood Flow and Metabolism. 2009;29(5):1048-58.

20. Knight RA, Nagaraja TN, Ewing JR, Nagesh V, Whitton PA, Bershad E, Fagan SC, Fenstermacher JD. Quantitation and localization of blood-to-brain influx by magnetic resonance imaging and quantitative autoradiography in a model of transient focal ischemia. Magn Reson Med. 2005;54(4):813-21.

21. van Tellingen O, Yetkin-Arik B, de Gooijer MC, Wesseling P, Wurdinger T, de Vries HE. Overcoming the blood-brain tumor barrier for effective glioblastoma treatment. Drug resistance updates : reviews and commentaries in antimicrobial and anticancer chemotherapy. 2015;19:1-12.

22. Carmeliet P, Jain RK. Angiogenesis in cancer and other diseases. Nature. 2000;407(6801):249-57.

23. Fukumura D, Jain RK. Tumor microvasculature and microenvironment: targets for anti-angiogenesis and normalization. Microvasc Res. 2007;74(2-3):72-84.

24. Eilken HM, Adams RH. Dynamics of endothelial cell behavior in sprouting angiogenesis. Curr Opin Cell Biol. 2010;22(5):617-25.

25. Schmitt M, Horbach A, Kubitz R, Frilling A, Haussinger D. Disruption of hepatocellular tight junctions by vascular endothelial growth factor (VEGF): a novel mechanism for tumor invasion. J Hepatol. 2004;41(2):274-83.

26. Carmeliet P. VEGF as a key mediator of angiogenesis in cancer. Oncology. 2005;69(Suppl 3):4-10.

27. Pardridge WM. Drug transport across the blood-brain barrier. J Cereb Blood Flow Metab. 2012;32(11):1959-72.

28. Lipinski CA. Drug-like properties and the causes of poor solubility and poor permeability. J Pharmacol Toxicol Methods. 2000;44(1):235-49.

29. Levin VA. Relationship of octanol/water partition coefficient and molecular weight to rat brain capillary permeability. J Med Chem. 1980;23(6):682-4.

30. van de Waterbeemd H, Camenisch G, Folkers G, Chretien JR, Raevsky OA. Estimation of blood-brain barrier crossing of drugs using molecular size and shape, and H-bonding descriptors. J Drug Target. 1998;6(2):151-65.

31. Fischer H, Gottschlich R, Seelig A. Blood-brain barrier permeation: molecular parameters governing passive diffusion. J Membr Biol. 1998;165(3):201-11.

32. Uchida Y, Ohtsuki S, Katsukura Y, Ikeda C, Suzuki T, Kamiie J, Terasaki T. Quantitative targeted absolute proteomics of human blood-brain barrier transporters and receptors. J Neurochem. 2011;117(2):333-45.

33. Sharom FJ. ABC multidrug transporters: structure, function and role in chemoresistance. Pharmacogenomics. 2008;9(1):105-27.
34. Hiesiger EM, Voorhies RM, Basler GA, Lipschutz LE, Posner JB, Shapiro WR. Opening the blood-brain and blood-tumor barriers in experimental rat brain tumors: the effect of intracarotid hyperosmolar mannitol on capillary permeability and blood flow. Ann Neurol. 1986;19(1):50-9.

35. Walker MD, Weiss HD. Chemotherapy in the treatment of malignant brain tumors. Adv Neurol. 1975;13:149-91.

36. Blasberg RG, Gazendam J, Patlak CS, Shapiro WS, Fenstermacher JD. Changes in blood-brain transfer parameters induced by hyperosmolar intracarotid infusion and by metastatic tumor growth. Adv Exp Med Biol. 1980;131:307-19.

37. Fidler IJ, Yano S, Zhang RD, Fujimaki T, Bucana CD. The seed and soil hypothesis: vascularisation and brain metastases. The Lancet Oncology. 2002;3(1):53-7.

38. Langley RR, Fidler IJ. The biology of brain metastasis. Clin Chem. 2013;59(1): 180-9.

39. Baba H, Nakahira K, Morita N, Tanaka F, Akita H, Ikenaka K. GFAP gene expression during development of astrocyte. Dev Neurosci. 1997;19(1):49-57.

40. Khurgel M, Ivy GO. Astrocytes in kindling: relevance to epileptogenesis. Epilepsy Res. 1996;26(1):163-75.

41. Yang Z, Wang KK. Glial fibrillary acidic protein: from intermediate filament assembly and gliosis to neurobiomarker. Trends Neurosci. 2015;38(6):364-74

42. Niranjan R, Nagarajan R, Hanif K, Nath C, Shukla R. LPS induces mediators of neuroinflammation, cell proliferation, and GFAP expression in human astrocytoma cells U373MG: the anti-inflammatory and anti-proliferative effect of guggulipid. Neurological sciences : official journal of the Italian Neurological Society and of the Italian Society of Clinical Neurophysiology. 2014;35(3):409-14.

43. Hozumi I, Chiu FC, Norton WT. Biochemical and immunocytochemical changes in glial fibrillary acidic protein after stab wounds. Brain Res. 1990;524(1):64-71.

44. Tsuji T, Shimohama S, Kamiya S, Sazuka T, Ohara O. Analysis of brain proteins in Alzheimer's disease using high-resolution two-dimensional gel electrophoresis. J Neurol Sci. 1999;166(2):100-6.

45. Troost D, Sillevis Smitt PA, de Jong JM, Swaab DF. Neurofilament and glial alterations in the cerebral cortex in amyotrophic lateral sclerosis. Acta Neuropathol. 1992;84(6):664-73.

46. Banati RB, Daniel SE, Blunt SB. Glial pathology but absence of apoptotic nigral neurons in long-standing Parkinson's disease. Movement disorders : official journal of the Movement Disorder Society. 1998;13(2):221-7.

47. Murayama S, Inoue K, Kawakami H, Bouldin TW, Suzuki K. A unique pattern of astrocytosis in the primary motor area in amyotrophic lateral sclerosis. Acta Neuropathol. 1991;82(6):456-61.

48. Laurence JA, Fatemi SH. Glial fibrillary acidic protein is elevated in superior frontal, parietal and cerebellar cortices of autistic subjects. Cerebellum (London, England). 2005;4(3):206-10.

49. Singh VK, Warren R, Averett R, Ghaziuddin M. Circulating autoantibodies to neuronal and glial filament proteins in autism. Pediatr Neurol. 1997;17(1):88-90

50. Rosengren LE, Ahlsen G, Belfrage M, Gillberg C, Haglid KG, Hamberger A. A sensitive ELISA for glial fibrillary acidic protein: application in CSF of children. J Neurosci Methods. 1992;44(2-3):113-9.

51. Aurell A, Rosengren LE, Karlsson B, Olsson JE, Zbornikova V, Haglid KG. Determination of S-100 and glial fibrillary acidic protein concentrations in cerebrospinal fluid after brain infarction. Stroke. 1991;22(10):1254-8.

52. Hausmann R, Riess R, Fieguth A, Betz P. Immunohistochemical investigations on the course of astroglial GFAP expression following human brain injury. Int J Legal Med. 2000;113(2):70-5.

53. Johnston-Wilson NL, Sims CD, Hofmann JP, Anderson L, Shore AD, Torrey EF, Yolken RH. Disease-specific alterations in frontal cortex brain proteins in schizophrenia, bipolar disorder, and major depressive disorder. The Stanley Neuropathology Consortium. Molecular psychiatry. 2000;5(2):142-9.

54. Chumbalkar VC, Subhashini C, Dhople VM, Sundaram CS, Jagannadham MV, Kumar KN, Srinivas PN, Mythili R, Rao MK, Kulkarni MJ, et al. Differential protein expression in human gliomas and molecular insights. Proteomics. 2005;5(4):1167-77.

55. Kovalchuk A, Kolb B: Chemo brain: from discerning mechanisms to lifting the brain fog-an aging connection. Cell Cycle (Georgetown, Tex) 2017:1-5.

56. Raffa RB. Is a picture worth a thousand (forgotten) words?: neuroimaging evidence for the cognitive deficits in 'chemo-fog'/'chemo-brain. J Clin Pharm Ther. 2010:35(1):1-9.

57. Castellon SA, Ganz PA, Bower JE, Petersen L, Abraham L, Greendale GA. Neurocognitive performance in breast cancer survivors exposed to adjuvant chemotherapy and tamoxifen. J Clin Exp Neuropsychol. 2004;26(7):955-69. 
58. Schagen SB, van Dam FS, Muller MJ, Boogerd W, Lindeboom J, Bruning PF. Cognitive deficits after postoperative adjuvant chemotherapy for breast carcinoma. Cancer. 1999;85(3):640-50.

59. Ahles TA, Saykin AJ, Furstenberg CT, Cole B, Mott LA, Skalla K, Whedon MB, Bivens $S$, Mitchell T, Greenberg ER, et al. Neuropsychologic impact of standard-dose systemic chemotherapy in long-term survivors of breast cancer and lymphoma. Journal of clinical oncology : official journal of the American Society of Clinical Oncology. 2002;20(2):485-93.

60. Kaiser J, Bledowski C, Dietrich J. Neural correlates of chemotherapy-related cognitive impairment. Cortex; a journal devoted to the study of the nervous system and behavior. 2014;54:33-50.

61. Seigers R, Fardell JE. Neurobiological basis of chemotherapy-induced cognitive impairment: a review of rodent research. Neurosci Biobehav Rev. 2011;35(3):729-41.

62. Seigers R, Loos M, Van Tellingen O, Boogerd W, Smit AB, Schagen SB. Cognitive impact of cytotoxic agents in mice. Psychopharmacology. 2015; 232(1):17-37.

63. Seigers R, Pourtau L, Schagen SB, van Dam FS, Koolhaas JM, Konsman JP, Buwalda B. Inhibition of hippocampal cell proliferation by methotrexate in rats is not potentiated by the presence of a tumor. Brain Res Bull. 2010; 81(4-5):472-6.

64. Seigers R, Timmermans J, van der Horn HJ, de Vries EF, Dierckx RA, Visser L, Schagen SB, van Dam FS, Koolhaas JM, Buwalda B. Methotrexate reduces hippocampal blood vessel density and activates microglia in rats but does not elevate central cytokine release. Behav Brain Res. 2010;207(2):265-72.

Ready to submit your research? Choose BMC and benefit from:

- fast, convenient online submission

- thorough peer review by experienced researchers in your field

- rapid publication on acceptance

- support for research data, including large and complex data types

- gold Open Access which fosters wider collaboration and increased citations

- maximum visibility for your research: over $100 \mathrm{M}$ website views per year

At $\mathrm{BMC}$, research is always in progress.

Learn more biomedcentral.com/submissions 